\title{
SPATIOTEMPORAL CHARACTERISTICS OF GROUNDWATER DEPTH IN XINGTAI CITY ON THE NORTH CHINA PLAIN: CHANGING PATTERNS, CAUSES AND PREDICTION
}

\author{
CAO, R. J. ${ }^{1}-$ JIANG, R. G. ${ }^{1,2^{*}}-$ ZHAO, Y. $^{2}-$ XIE, J. C. ${ }^{1}-$ YU, X. ${ }^{1}$ \\ ${ }^{1}$ State Key Laboratory of Eco-hydraulics in Northwest Arid Region of China, Xi'an University \\ of Technology, Xi'an 710048, China \\ ${ }_{2}^{2}$ State Key Laboratory of Simulation and Regulation of Water Cycle in River Basin, China \\ Institute of Water Resources and Hydropower Research, Beijing 100038, China \\ ${ }^{*}$ Corresponding author \\ e-mail:jrengui@163.com \\ (Received 24 $4^{\text {th }}$ Apr 2020; accepted $14^{\text {th }}$ Aug 2020)
}

\begin{abstract}
The analysis of spatiotemporal characteristics for groundwater depth can provide a theoretical basis for comprehensive management of groundwater and sustainable development of ecology and environment. The paper investigated the changing patterns of groundwater depth, and further explored the linear and nonlinear relationships between groundwater depth and four potential influencing factors using grey relational analysis and wavelet coherence during 2000-2017. The multiple linear regression and Random Forest (RF) models were proposed to predict the groundwater depth. Taking Xingtai city on the North China Plain as an example, the results indicate that: (1) The groundwater depth in a shallow aquifer has deepened significantly after 2006, and decreased from northwest to southeast. A clear upward trend was detected in the southeast region of the study area. (2) The change of groundwater depth is related to the consumption during agricultural irrigation period and the supply of heavy rainfall during flood season, and the deepest groundwater depth was detected in June. (3) The cross-correlation analysis demonstrated that main influencing factors of groundwater depth are precipitation and temperature. (4) The comparison between actual value and prediction value indicated that the RF model has better accuracy in predicting the groundwater depth than the multiple linear regression model.
\end{abstract}

Keywords: groundwater comprehensive treatment, spatial and temporal variability, non-parametric Mann-Kendall test, grey relational analysis, wavelet coherence, random forest model

\section{Introduction}

Groundwater is one of important sources of water for humans, especially in the arid and semi-arid areas (e.g., Algeria, Australia, China, Egypt, and Western United States) where water resources are insufficient, or the surface water is heavily polluted, due to serious ecological and environmental issues. Water for human life, agricultural irrigation and industrial activities mainly depends on the exploitation of groundwater resources (Alley et al., 2002; Oki et al., 2006; Wada et al., 2012). Globally, the groundwater accounts for 29.9\% of all global freshwater resources (Shiklomanov, 2000; $\mathrm{Li}$ and Qian, 2018) and the shortages of water resource have become one of the most important challenges to humankind (Robertson and Sharp, 2013; Wang et al., 2016). Water resources problems are common throughout China (Jiang, 2009), especially, the North China Plain (NCP), which has serious groundwater problems including the overexploitation of groundwater or the groundwater pollution. The NCP is the biggest plain of China, and its aquifer system extends about $122,000 \mathrm{~km}^{2}$, supporting over $11 \%$ of China's population and 14\% of arable land (Pang et al., 2020). The groundwater has provided more than $70 \%$ of the NCP's total water supply, which can support 
agricultural irrigation, daily life, and economic development (Liu et al., 2011). However, the overexploitation of groundwater has accelerated since 1970s, and NCP has gradually become one of the most groundwater over-pumped zones around the world, with a long belt along the Beijing-Shijiazhuang-Xingtai area (Shah et al., 2003; Zhang and $\mathrm{Li}, 2013$ ). The groundwater depth has declined more than $10-60 \mathrm{~m}$ in $40 \%$ of the entire NCP (Zheng et al., 2010). To avoid the problem of groundwater overexploitation, the government has already taken action to reduce groundwater consumption and adopt measures to adjust agricultural planting structure. For more scientific and effective management, it is important to analyze the changing patterns and causes of groundwater depth. The spatiotemporal evolution of groundwater systems is affected by many factors, including both natural and man-made factors, such as meteorological and hydrological conditions, geological environment, economic development, industrialization, and urbanization. Various measures have been taken to change the balance between groundwater consumption and supply. The analysis of the changes and causes of groundwater depth under the multiple influencing factors are thus of great significance for sustainable development of groundwater resources.

Many previous studies have focused on the changes of groundwater depth, to explore the ecological environment of groundwater resources, and to find a sustainable development path (Ebraheem et al., 2004). Generally, the studies on the spatial-temporal characteristics of groundwater depth have mainly combined with mathematical models. E.g., Manap et al. (2014) drew a map of groundwater potential in the Langat Basin, Malaysia based on probabilistic-based frequency ratio model (FR), and analyzed the spatial relationships between groundwater depth and various hydrological elements. The results indicated that FR model is a high precision way to validate the groundwater potential map (Manap et al., 2014). Naghibi et al. (2016) used the boosted regression tree (BRT), classification and regression tree (CART), and Random Forest (RF) models in conjunction with GIS to draw a groundwater potential mapping, and evaluated the simulation accuracy of the three models. The results showed that the BRT model produced the best prediction value in predicting locations of springs (Naghibi et al., 2016). With the development of urbanization, the impact of climate change and human life on groundwater continues to aggravate. Research scholars focus on the analysis of impact on groundwater changes from both natural factors and human activities. Green et al. (2011) proposed exploring the relationship between groundwater systems and climate change from two aspects: groundwater quality and groundwater volume (Green et al., 2011). Vidal et al. (2000) analyzed the spatiotemporal characteristics of groundwater chemical composition from the perspective of groundwater quality (Vidal et al., 2000). In addition, the groundwater system environment is complicated, and analyzing the potential influencing factors of groundwater is an important research direction. The RF model has been proved to be useful in discovering potential influence factors and predicting target value, and it can improve the prediction accuracy without a significant increased calculation. Iverson et al. (2008) used RF model to draw groundwater potential maps (GPMs), proving that the model is an effective method for drawing GPMs (Iverson et al., 2008).

The objectives of this study include: (1) To analyze the characteristics of groundwater depth from aspects of inter-annual, intra-annual, depth variation and spatial distribution. The non-parametric Mann-Kendall test is used to analyze the temporal and spatial trends and the catastrophe point of groundwater depth. (2) To further reveal the physical mechanism behind the changes of groundwater depth and its 
influencing factors, this paper explored the spatiotemporal characteristics of groundwater depth and relationships between several main influencing factors. The grey relational analysis and wavelet coherence are used to analyze the main influencing factors and their potential relationships. The multiple linear regression and RF models are used to predict the groundwater depth using the influencing factors as predictors, and the accuracy of two models are further compared. (3) To investigate the characteristics and causes of groundwater depth change, taking Xingtai city on the North China Plain as an example, which should be of great significance to coordinate the development of groundwater resources and maintain the stability of the water ecology.

\section{Material and methods}

\section{Study area}

The NCP is located in the middle part of the North China, and it refers to the region bordered to the north of the Yanshan Mountains, and west of the Taihang Mountains, to the south by the Yellow River, and to the northeast by the Bohai Gulf (Zhang et al., 2003). The NCP includes all the plains of the northern parts of Shandong and Henan Provinces, Beijing Municipality, Tianjin Municipality and Hebei province. Xingtai city is located at the central and southern part of Hebei province, and the surface water resources are scarce and groundwater is serious overexploited (Li et al., 2005; Sun et al., 2010). Figure 1 shows the locations of the study area and spatial distribution of the groundwater monitoring stations.

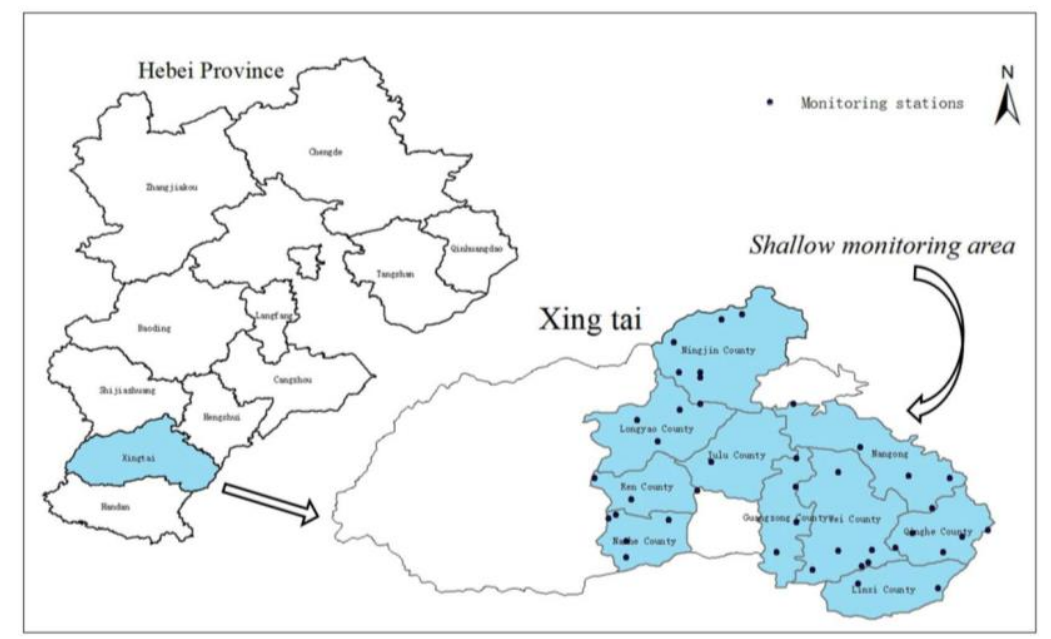

Figure 1. Study area and locations of groundwater monitoring stations in the shallow aquifer of Xingtai city, China

Xingtai city is located between the longitude of $113^{\circ} 52^{\prime}-115^{\circ} 49^{\prime} \mathrm{E}$ and the latitude of $36^{\circ} 50^{\prime}-37^{\circ} 47^{\prime} \mathrm{N}$. It has a total of 18 counties and cities with a total area of $12,456 \mathrm{~km}^{2}$, of which the plain area is $8911 \mathrm{~km}^{2}$ and the mountain area is $3545 \mathrm{~km}^{2}$. Xingtai city has a temperate continental monsoon climate. The average temperature is about $13.1^{\circ} \mathrm{C}$, and the precipitation is about $470 \mathrm{~mm}$ per year which rainfall is concentrated in summer. The types of groundwater mainly include confined water and 
phreatic water. The confined water is generally below $100 \mathrm{~m}$ and is hard to mine. The groundwater in the shallow aquifer is the main source of agricultural and domestic water. This study mainly focuses on the groundwater in the shallow aquifer. Xingtai city is located in the transition zone from the mountain area to the plain area. The shallow groundwater monitoring stations are distributed in the eastern plain, including the water resources area of Luxi Plain, Heilonggang District, and Luxi District.

\section{Data collection}

The groundwater depth data were obtained from the Hydrological and Water Resources Survey Bureau of Xingtai city, Hebei province. The groundwater depth data from 41 monitoring stations in the plain area of Xingtai city during 2000-2017 were obtained to analyze the groundwater depth characteristics of the shallow aquifer. The Shapefile of the study area was downloaded from the Global Aviation Data Management (GADM) at https://gadm.org/download_country_v3.html to analyze the spatial distribution of groundwater depth using ArcGIS. The nature factors that might affect the groundwater depth such as precipitation, temperature, and evapotranspiration (ET) data from nine counties were used in the study. These data are obtained from Xingtai city meteorological bureau. The Gross Domestic Product (GDP) of Xingtai city was selected as the artificial factor affecting the depth of groundwater, which collected from the statistical yearbook of Xingtai city for the period of 2000-2017.

\section{Research methodology}

\section{Non-parametric Mann-Kendall test}

The trends of groundwater depth for 41 monitoring stations were analyzed using the non-parametric Mann-Kendall test method from 2000 to 2017. The Kendall's $S$ is calculated using Equation 1.

$$
S=\sum_{k=1}^{n-1} \sum_{j=k+1}^{n} \operatorname{sgn}\left(x_{j}-x_{k}\right) \quad \operatorname{sgn}\left(x_{j}-x_{k}\right)=\left\{\begin{array}{ll}
1, & \text { if }\left(x_{j}-x_{k}\right)>0 \\
0, & \text { if }\left(x_{j}-x_{k}\right)=0 \\
-1, & \text { if }\left(x_{j}-x_{k}\right)<0
\end{array}\right\}
$$

where $n$ is the length of $X$, in this experiment, $n=18$.

The standardized $Z$ statistic is provided in Equation 2 (Shadmani et al., 2012; Jiang et al., 2015; Jiang et al.,2020).

$$
Z=\left\{\begin{array}{cccc}
\frac{S-1}{\sqrt{\operatorname{Var}(S)}} & , & \text { if } & S>0 \\
0 & , & \text { if } & S=0 \\
\frac{S+1}{\sqrt{\operatorname{Var}(S)}} & , & \text { if } & S<0
\end{array}\right\}
$$

The formula is normal distribution. $\operatorname{Var}(S)$ is the variance of statistic $S$. The positive values of $Z$ indicate increasing trends of groundwater depth, negative values for decreasing trends, and $Z=0$ is stationary. The null-hypothesis at $\alpha$ significance level 
will be rejected if $|Z|>Z_{1-\alpha / 2}$, indicating statistically significant trends. Two significance levels of $10 \%$ and $5 \%$ are used in this paper to provide trends of groundwater depth, which corresponding the $|Z|$ is greater than 1.64 and 1.96.

\section{Wavelet coherence}

The wavelet analysis is used to reveal the nonlinear relationship between groundwater depth and its influencing factors. The wavelet coherence (WTC) is to detect regions with significant coherence (Jiang et al., 2018; Jiang et al., 2019b; Yan et al., 2020). The wavelet defines two time series $X_{n}$ and $Y_{n}$ as $W^{X Y}=W^{X} W^{Y^{*}}$, where * is complex conjugate. The power spectrum $P_{k}^{X}$ and $P_{k}^{Y}$ of $X_{n}$ and $Y_{n}$ are defined as Equation 3.

$$
D\left(\frac{\left|W_{n}^{X}(s) W_{n}^{Y^{*}}(s)\right|}{\sigma X \sigma Y}<p\right)=\frac{Z_{v}(p)}{v} \sqrt{P_{k}^{X} P_{k}^{Y}}
$$

where $Z_{v}(P)$ is the confidence degree of $P$, which is the square root of the wavelet spectrum.

The phase angle of the wavelet coherence is defined as Equation 4.

$$
a_{m}=\arg (X, Y)=\arg \left[\sum_{i=1}^{n} \cos \left(a_{i}\right), \sum_{i=1}^{n} \sin \left(a_{i}\right)\right]
$$

The standard deviation of the wavelet phase angle is defined as Equation 5.

$$
s=\sqrt{-2 \ln (R / n)}=\sqrt{-2 \ln \left(\sqrt{X^{2}+Y^{2}} / n\right)}
$$

The WTC $R_{n}^{2}(S)$ is the square of the of $X_{n}$ and $Y_{n}$, and $R_{n}^{2}(S) \in[0,1]$, normalized by the smoothed wavelet power, where [.] smooth the wavelet spectrum in different time and scale, calculated using Equation 6 (Jiang et al., 2014).

$$
R_{n}^{2}(s)=\frac{\mid S\left[s^{-1} W_{n}^{X Y}(s)\right]^{2}}{S\left[s^{-1}\left|W_{n}^{X}(s)\right|^{2}\right] \bullet S\left[s^{-1}\left|W_{n}^{Y}(s)\right|^{2}\right]}
$$

where $W_{n}^{X}(s)$ and $W_{n}^{Y}(s)$ are the wavelet transform of $X_{n}$ and $Y_{n}$. The statistical significance level of the WTC is estimated using Monte Carlo methods. The smoothing operator $S$ of $W_{n}^{X Y}(s)$ in numerator and wavelet power spectrum (WPS) in denominator is given in Equation 7 (Jevrejeva et al., 2003; Jiang et al., 2019a).

$$
S(W)=S_{\text {scale }}\left\{S_{\text {time }}\left[W_{n}(s)\right]\right\}
$$


where $S_{\text {scale }}$ and $S_{\text {time }}$ are denoted smoothing along the wavelet scale axis and in time. $S_{\text {scale }}$ and $S_{\text {time }}$ are defined as Equation 8 and Equation 9.

$$
\begin{gathered}
\left.S_{\text {scale }}(W)\right|_{s}=\left.\left(W_{n}(s) * c_{1} \frac{-t^{2}}{2 s^{2}}\right)\right|_{s} \\
\left.S_{\text {time }}(W)\right|_{n}=\left(\left.W_{n}(s) * c_{2} \Pi(0.6 s)\right|_{n}\right.
\end{gathered}
$$

where $c_{1}$ and $c_{2}$ are the normalized constants, $\Pi$ is the rectangle function, and 0.6 is the scale de-correlation length for the Morlet wavelet.

\section{Grey relational analysis}

The grey relational analysis is used to analyze the degree of correlation between the influencing factors and groundwater depth, and to determine the main factors. The main evaluation model is determined in Equation 10.

$$
R=Y \times W
$$

where $R$ is the comprehensive evaluation result vector of indicators, $Y$ is the evaluation matrix of indicators, and $W$ is the weight vector of indicators. The influencing factors selected in this study are rainfall, temperature, evapotranspiration, and GDP. The target value vector is determined in Equation 11.

$$
F=\left\lfloor x_{1}^{i}, x_{2}^{i}, x_{3}^{i}, x_{4}^{i}\right\rfloor
$$

where $x_{k}^{i}$ is the original value of the index $k$ in year $i$, and $(i=1,2, \cdots 18),(k=1,2, \cdots, 4)$.

The physical meanings of the indicators are different, so the dimensions of the data are not the same. It is not easy to directly compare them, and it's necessary to perform the dimensionless processing of the data. The Equation 12 is used for indicator normalization.

$$
C_{k}^{i}=\frac{x_{k}^{i}-x_{k 1}}{x_{k 2}-x_{k}^{i}}
$$

where $x_{k 1}$ is the minimum value of the $k$ index, and $x_{k 2}$ is the maximum value of the $k$ index.

The comprehensive evaluation is calculated by the correlation coefficient between each comparison column and the corresponding element in the reference column, which is determined as Equation 13.

$$
\xi_{\mathrm{i}}(k)=\frac{\min _{i} \min _{k}\left|C_{k}^{*}-C_{k}^{i}\right|+\rho \max _{i} \max _{k}\left|C_{k}^{*}-C_{k}^{i}\right|}{\left|C_{k}^{*}-C_{k}^{i}\right|+\rho \max _{i} \max _{k}\left|C_{k}^{*}-C_{k}^{i}\right|}
$$


where $\rho$ is the resolution coefficient, and $0<\rho<1$. Normally, $\rho=0.5$.

The correlation degree refers to the average value of the correlation coefficient between each influencing element and the corresponding element in the reference column, which is determined as Equation 14.

$$
r_{i}=\frac{1}{m} \sum_{k=1}^{m} \xi_{i}(k)
$$

According to $r_{i}$, factors related to the reference sequence are obtained. A larger $r_{i}$ indicates that the factor is more closely related to the dependent variable.

\section{Random forest $(R F)$ model}

The statistical model and artificial intelligence model are two common types of predictive models (Breiman et al., 2010). The statistical models take a long time to analyze the data of long-term series, and it is difficult to accurately predict the trend of the dependent variable. The artificial intelligence model has strong fitting ability and high intensive reading, so the random forest model is used to predict the groundwater depth in this study. Breiman et al. (2001) proposed the random forest model based on the regression tree model, which is widely used to explain the effect of multivariate on the dependent variable and to predict the dependent variable. The principle of RF model is to randomize the use of variables (columns) and data (rows), so that the classification trees can be generated, which can significantly improve the prediction accuracy (Van et al., 2014).

There are two key indicators in the RF model including the average reduction of standardity and Gini coefficient (Hong et al., 2017), indicating the number of trees (ntree) and the number of variables (mtry). The ntree changes according to dataset size, for datasets that are small, 50 trees may suffice. However, large datasets might require 100 or more trees. The ntree is often set to 100 in experiments (Bahareh et al., 2019). In this experiment, we randomly selected $70 \%$ of the dataset to calibrate the RF model. The remainder (30\%) was used for accuracy testing. Variable importance is obtained from Equation 15.

$$
V I_{m p}\left(Y_{j}\right)=\frac{1}{N} \sum_{t} \operatorname{errOOB} B_{t}^{j}-\operatorname{errOOB}_{t}
$$

In Equation 15, $N$ is the total number of trees. The function $V I_{m p}\left(Y_{j}\right)$ indicates the importance of the variable. The term $\operatorname{errOOB}_{t}$ is the prediction error when all factors are considered, whereas $\operatorname{errOOB} t_{t}^{j}$ is the error after removing the $j$ variable.

The RF model determines the importance of each variable based on the impact of the overall error on the model. By fitting the correlation between variables, it can be applied to different types of variables and missing values (Pourghasemi et al., 2013). The RF model can avoid over fitting and bias due to variable diversity (Rahmati et al., 2016). The Python is used for programming. The groundwater depth is used as independent variable, and the evolution factors such as precipitation, temperature, evapotranspiration, and GDP that affect the depth of groundwater are used as independent variables, to predict the groundwater depth for the period of 2000-2017. 


\section{Results and discussion}

\section{Spatial and temporal variability of groundwater depth}

\section{Temporal distribution of interannual variation of groundwater depth}

Figure 2 shows the relationship between groundwater depth and precipitation in Xingtai city from 2000 to 2017, based on the average groundwater depth and precipitation data monitored at the observation wells in the study area. It can be seen that the fluctuation of groundwater depth is generally consistent with the change of annual precipitation, indicating that precipitation is one of the influencing factors of groundwater depth. From the trend line, it can be seen that the groundwater depth in Xingtai city has deepened, and the Person's correlation coefficient is 0.95 showed that the changes were statistically significant. The groundwater depth has dropped $5.56 \mathrm{~m}$ from $16.75 \mathrm{~m}$ in 2000 to $22.31 \mathrm{~m}$ in 2017 . The decrease rate of groundwater depth is $0.7 \mathrm{~m} / \mathrm{a}$, and the descending rate is relatively large. The groundwater depth has been in a continuous downward trend from 2003 to 2012. The depth has slightly rebounded from 2015 to 2017, mainly because Hebei province unveiled effective engineering and non-engineering measures for groundwater overexploitation control in 2014.

The uneven distribution of water resources in Xingtai city, and the conditions of the groundwater depth also varied in counties. According to the counties of each monitoring station, the annual average groundwater depth in each county is calculated from 2000 to 2017, as shown in Figure 3. The groundwater depth in Heilonggang Plain including Julu county, Guangzong county, Nangong county and Wei county, is relatively shallow and the variations are within $5 \mathrm{~m}$ from 2000 to 2017. However, the depth is deep and changes more than $10 \mathrm{~m}$ in the Luxi Plain including Nanhe, Longyao and Ren counties. The Longyao county has the maximum change of groundwater depth, and it has declined $1.97 \mathrm{~m} / \mathrm{yr}$.

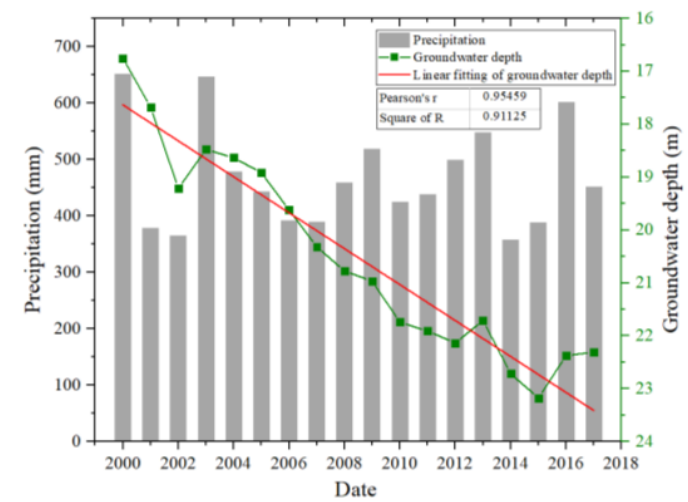

Figure 2. Average groundwater depth and precipitation

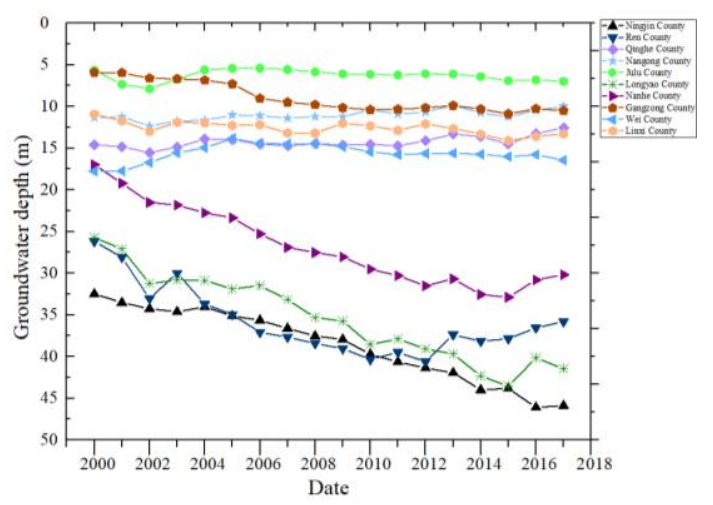

Figure 3. Groundwater depth of counties

\section{Spatial distribution of interannual variation of groundwater depth}

Figure 4 shows the spatial distribution of interannual changes in the groundwater depth in Xingtai city at 2000, 2005, 2010 and 2017 using Kriging interpolation method. It can be seen that the groundwater depth in the northwest of the study area is deeper than that in the southeast region. The annual average groundwater depth has increased from $18.25 \mathrm{~m}$ to $23.97 \mathrm{~m}$, indicating an overall deepening trend. In 2000, the 
groundwater depth in northwestern areas of Ningjin county and Longyao county were deeper than in other counties, and the groundwater overexploitation was serious. However, it rebounded significantly in 2005. The overall groundwater depth of Julu County and Guangzong county was relatively shallow in 2000. As the overexploitation has increased, the groundwater depth has gradually deepened. The groundwater depth in the northwestern part of Nangong city was shallow in 2000, but the increase of overexploitation had decreased by 2015. It has rebounded under the implementation of overdraft control measures during 2015-2017. In the southeast of Wei County and the northwest of Linxi County, the groundwater depth dropped sharply in 2010.

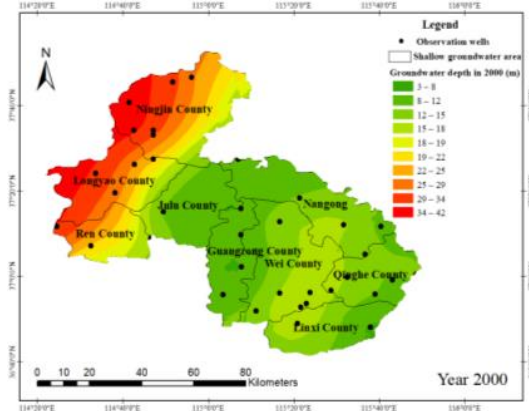

(a)

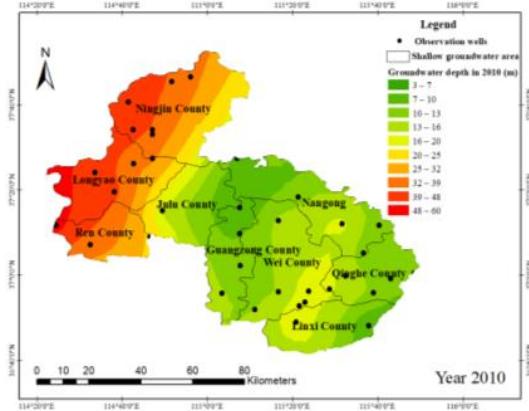

(c)

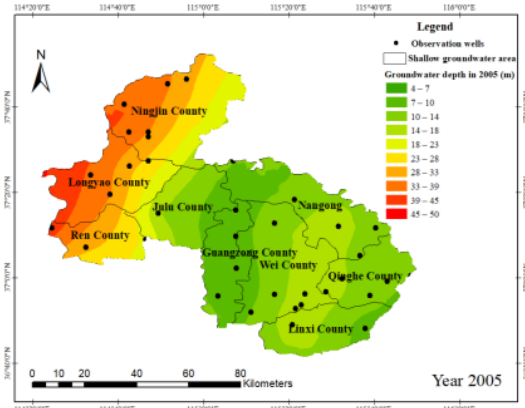

(b)

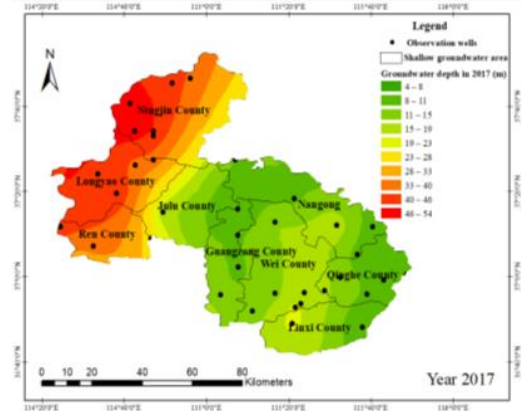

(d)

Figure 4. Spatial distribution of interannual changes in groundwater depth (a) Groundwater depth in 2000; (b) Groundwater depth in 2005; (c) Groundwater depth in 2010; (d)

Groundwater depth in 2017

The results show that the groundwater depth in Xingtai city has deepened for the period of 2000-2017, and the rate of change has increased from 2000 to 2017, which is mainly consistent with previous results. For example, Li et al. (2014) found that the groundwater levels showed an overall decreasing trend over the past 50 years, and an increase in the groundwater depth at a rate of approximately $0.36 \mathrm{~m} / \mathrm{a}$.

\section{Intraannual variability of groundwater depth}

Figure 5 shows the trends of monthly groundwater depth in two typical years including 2016 and 2017, to analyze the intral-annual variations of groundwater depth in Xingtai city. The trends of groundwater depth in different years are similar, and June groundwater depth is the deepest. The annual spring irrigation period is from March to June, and agricultural irrigation is mainly from the exploitation of shallow groundwater, which made the groundwater depth deeper. With the increase of rainfall from July to September, the high permeability of the aquifer makes the groundwater recharged and 
the groundwater depth rebounded. Crops like winter wheat are at the seedling stage from October to December, during which time the water demand is reduced, domestic water is stable, irrigation and replenishment are in a relatively balanced period, and thus the groundwater level is basically stable during this period. The trend throughout the year shows that the change of groundwater depth is related to the consumption during agricultural irrigation period and the replenishment of rainfall during flood season.

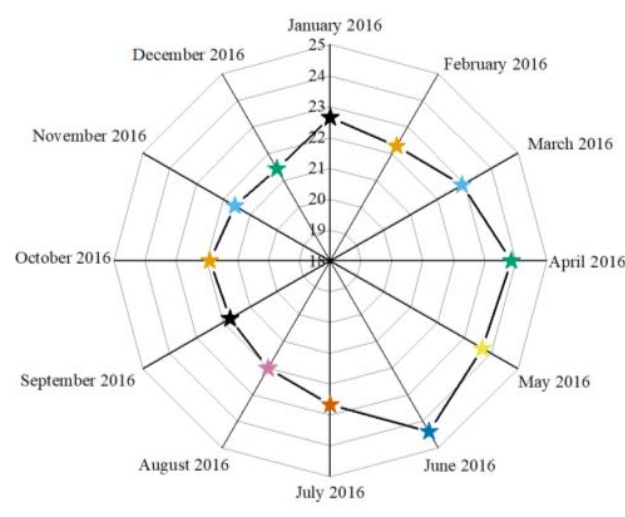

(a)

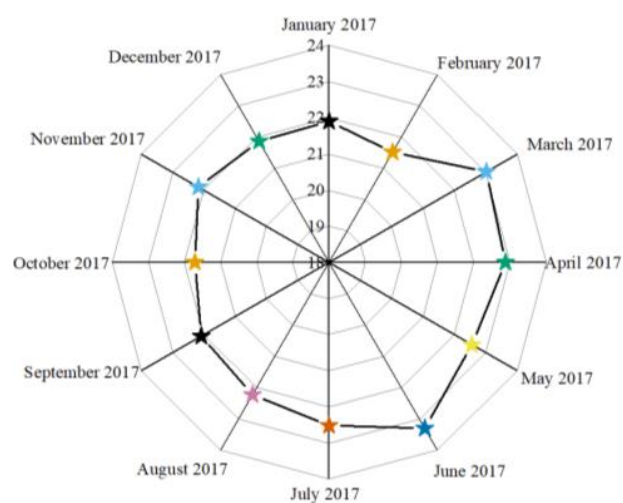

(b)

Figure 5. Trend of groundwater depth in typical years (a) Trend of monthly groundwater depth in 2016; (b) Trend of monthly groundwater depth in 2017

The results showed that during the crops growing season from March to June, the groundwater depth is deep, which is mainly consistent with previous results. For example, Wang et al. (2009) found that the lowest water table was in the dry season with strong evaporation and less precipitation. Zheng et al. (2019) demonstrated that cultivation intensified water evaporation in the top soil layer (upper 10-20 cm), and the groundwater depth is reduced. The results showed that from July to September, the groundwater depth is recovered due to the increase of the rainfall, which is also mainly consistent with previous results. Wang et al. (2009) detected that the water table increases rapidly due to recharge by precipitation.

\section{Spatial distribution of trends and abrupt change of groundwater depth}

Figure 6 shows the spatial distributions of the trends of groundwater depth groundwater depth trends for 41 monitoring stations in the shallow aquifer of Xingtai city from 2000 to 2017 using the non-parametric Mann-Kendall test. The positive magnitude indicates the increasing trend of groundwater depth, and vice versa for decreasing trend. The results showed that eleven stations had downward trends in groundwater depth (the blue downward triangle), indicating that the groundwater depth has become shallower. All of them are distributed in the southeast of Xingtai city. Four stations that had significant decreasing trend at $10 \%$ significant level were located in the northern Guangzong county, central Nangong city, southern Wei county and northern Qinghe county, indicating clear rising trends of groundwater depth. However, there are six stations located in the middle of the shallow area have increasing trends. The stations located in the west and south of the shallow area shown significant upward trends (the purple upward triangle) at $5 \%$ significant level, indicating that the 
groundwater depth will continue to decline, and the groundwater in these regions are overexploited which should be emphasized for governing.

Figure 7 shows the result of abrupt change of the groundwater depth using Mann-Kendall test. It can be seen that the groundwater depth in Xingtai city has increased since the $21^{\text {st }}$ century $(U F>0, U B>0)$, and it has significantly increased at significant level of $5 \%$ after 2005, indicating that the amount of groundwater exploitation has significantly increased since 2005. The results are mainly consistent with previous results. For example, Liu et al. (2017) found that the groundwater level continues to decline in the $21^{\text {st }}$ century. At the same time, a sudden change in groundwater depth occurred in 2006, and the problem of groundwater overexploitation are beginning to be prominent.

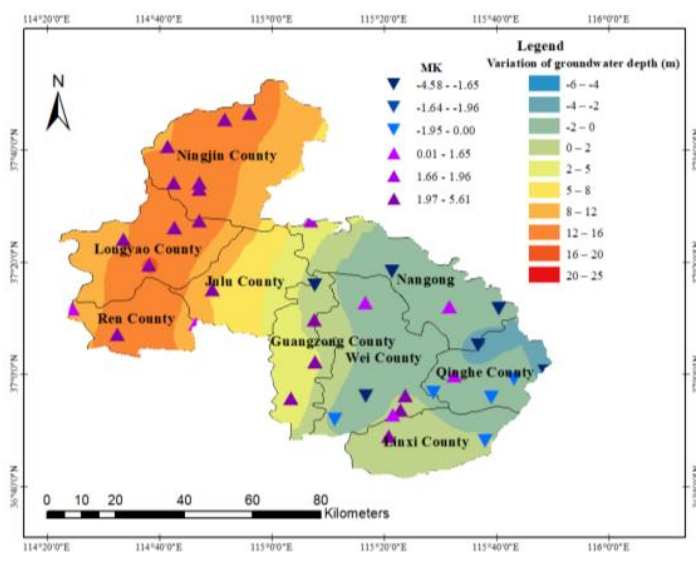

Figure 6. Non-parametric Mann-Kendall test Figure 7. Mann-Kendall abrupt change test of of groundwater depth in shallow aquifer

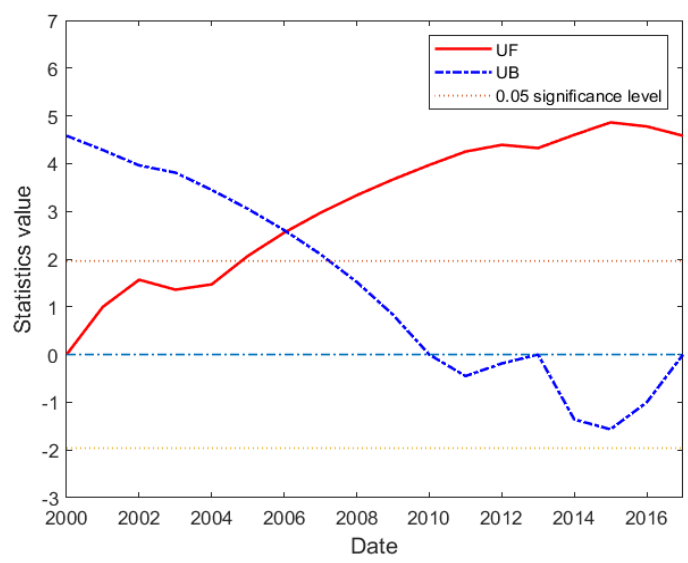

groundwater depth

\section{The influencing factors of groundwater depth and their relationships}

Correlation and wavelet coherence analysis

The recharge of groundwater system in Xingtai city of Hebei province mainly originated from precipitation, river and irrigation infiltration. The excretion is mainly from groundwater exploitation and evapotranspiration of shallow aquifer groundwater. In addition, some potential factors also affect the change of groundwater depth. The annual average precipitation, evapotranspiration of shallow aquifer groundwater, annual average temperature, and GDP of Xingtai city are selected as influencing factors in this following analysis.

The importance of the influencing factors is obtained by using the gray relational analysis. From the correlation between the influencing factors and the groundwater depth, it can be obtained that the main influencing factor of the groundwater depth is the precipitation, followed by the temperature, and the correlation degrees are 0.9965 and 0.7193, respectively. It is indicated that increasing the amount of groundwater recharge is the first task to improve the groundwater overexploitation problems. The correlation degree between GDP of Xingtai city and the groundwater depth is 0.5652. The correlation coefficient between the evapotranspiration of shallow groundwater and the groundwater depth is 0.5192 .

The wavelet coherence is further used to analyze the nonlinear relationships between groundwater depth and each influencing factor including rainfall, temperature (Tem), 
evapotranspiration, GDP, as shown in Figure 8. The results are compared with the importance scores obtained from the grey relational analysis. It can be seen that the groundwater depth is negatively correlated with the rainfall, and negatively correlated with the temperature. The groundwater depth is negatively correlated with GDP in Xingtai city for the period of 2000-2017.

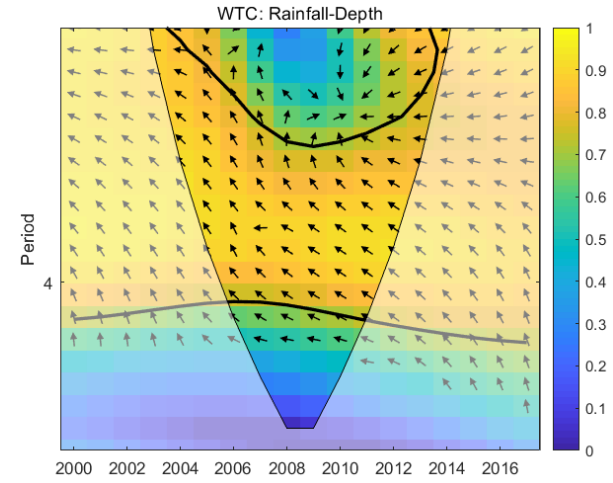

(a)

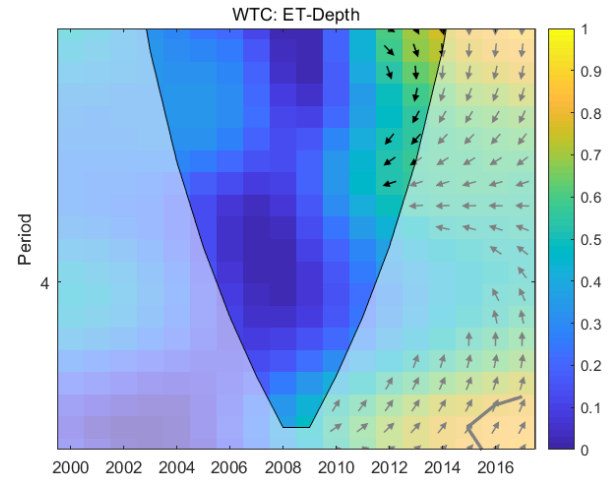

(c)

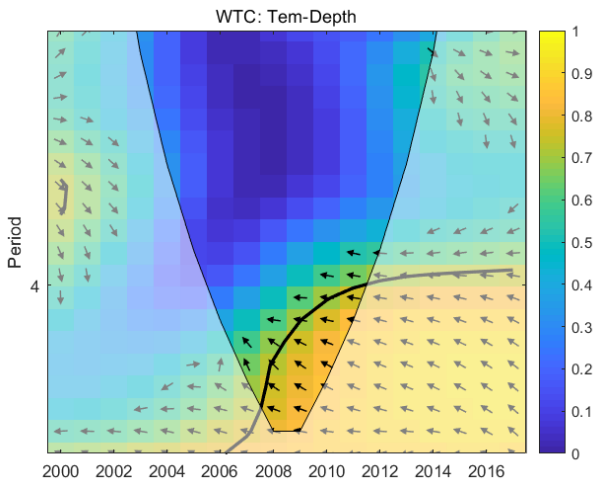

(b)

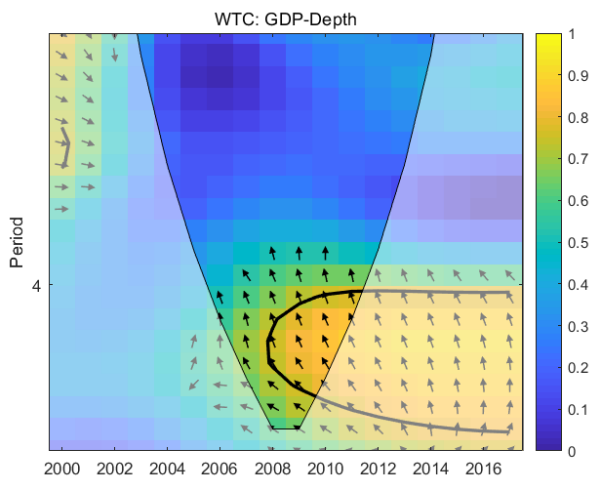

(d)

Figure 8. The WTCs between groundwater depth and (a) Rainfall, (b) Temperature (Tem), (c) evapotranspiration, (d) GDP in Xingtai city for the period of 2000-2017

The results revealed in Figure 8 using wavelet coherence are generally consistent with the results using gray correlation analysis, indicating that the wavelet coherence method should be more feasible to investigate the nonlinear relationships between groundwater depth and influencing factors. The results indicated that precipitation is the mainly influencing factor of the groundwater depth, which is mainly consistent with previous results. For example, Liu et al. (2016) showed that large rainstorms can play an important role in regional shallow groundwater resources to recharge the groundwater. Meng et al. (2015) found that the precipitation infiltration recharge is closely related to the water table decrease. The results of the relationship between temperature and groundwater depth is mainly consistent with the previous results of Zhang et al. (2014), who detected that the average temperature of NCP had a close relationship with groundwater depth. The results showed that there is no significant correlation between evapotranspiration and groundwater depth, which is mainly concurred with Bai et al. (2017), who demonstrated that the total agriculture ET stayed relatively stable, in spite of the great adjustment of cropping pattern to reduce the exploitation of groundwater. 
Tian et al. (2016) found that the factors such as the evaporation are less relevant to the groundwater depth variations, which concurred with our results.

\section{Prediction of groundwater depth}

The precipitation, temperature, evapotranspiration and GDP of Xingtai city are used as independent variables in multiple linear regression model, and the groundwater depth is dependent variable. The multiple linear regression is given in Equation 16, which can be obtained using Statistic Package for Social Science (SPSS) software.

$$
y=-0.005 x_{1}-1.703 x_{2}-0.001 x_{3}+0.003 x_{4}+45.911
$$

where $x_{1}$ is the average annual precipitation, $x_{2}$ is the average annual temperature, $x_{3}$ is the evapotranspiration of shallow aquifer groundwater and $x_{4}$ is the GDP of Xingtai city for the period of 2000-2017.

The relative error is used to evaluate the simulation accuracy of the regression equation. Figure $9 a$ shows the changes of the measured and predicted values of groundwater depth using multiple linear regression. It can be seen that the absolute value of the relative error of the groundwater depth during eighteen years is within $7 \%$, and the relative error in 2000, 2001 and 2008 exceeded 5\%. The correlation coefficient between prediction and actual values is 0.94 . It shows that the predicted value obtained by the multiple linear regression model is consistent with the actual value, which should be an effective method for predicting the depth of groundwater.

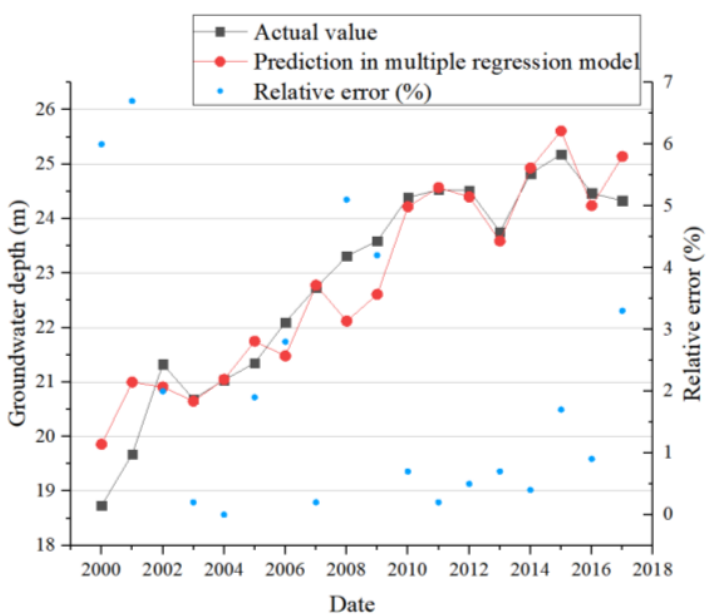

(a)

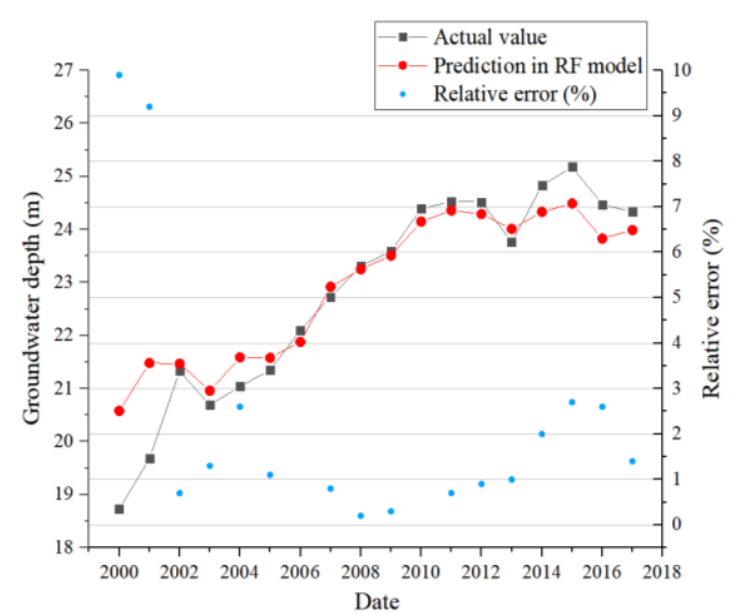

(b)

Figure 9. The prediction and the actual value of groundwater depth by using (a) Multiple linear regression, and (b) $R F$ model

Similarly, the above four factors are used as independent variables to establish a RF model to predict the groundwater depth, as shown in Figure 9b, which showed that the prediction can better fit the actual value, and the correlation coefficient between the actual value and the prediction value is 0.97 . Except for the relative error is $9 \%$ and the standard deviation is 1.2 in 2000 and 2001, the absolute relative errors of the prediction and actual values are less than $3 \%$, and the standard deviation is less than 0.5 in other years. The prediction error and the standard residual value are small, indicating that the 
RF model is more accurate in analyzing the changes of dependent variables under the influence of multiple factors and predicting the dependent variable.

After comparing the prediction values obtained by two models, it can be concluded that the multiple linear regression is an effective method to predict the groundwater depth using precipitation, temperature, evapotranspiration and GDP as predictors (Figure 9a). However, the random forest model has higher accuracy than that of multiple linear regression (Figure 9b), which is mainly concurred with Chen et al. (2019), who found that the prediction value of the RF model are ideal in the research of long time series.

\section{Conclusions}

The paper investigated the spatial and temporal characteristics of groundwater depth for the period of 2000-2017 in a typical city in NCP. The linear and nonlinear relationships between groundwater depth and influencing factors including precipitation, temperature, evapotranspiration and GDP were examined using gray correlation analysis and wavelet coherence. The multiple linear regression and random forest models were used to obtain the predictions of groundwater depth using the influencing factors as potential predictors. The main conclusions are summarized as follows:

(1) The groundwater depth in shallow aquifer of Xingtai city has generally deepened since the $21^{\text {st }}$ century, and it has significantly increased after 2005 . There has been a sudden change of groundwater depth in 2006. The problem of groundwater overexploitation has become prominent. The groundwater depth varied in different regions and different time. In the northwest, the groundwater depth was deep and still had a tendency to deepen. Therefore, it should be the key region for groundwater treatment. After unveiling the groundwater overdraft control measures in 2014 in Hebei province, the groundwater depth in shallow aquifer recovered from 2015 to 2017. In the eastern region, the groundwater depth has rebounded significantly.

(2) The change of groundwater depth is related to the consumption during agricultural irrigation period and the replenishment of rainfall during flood season. The deepest groundwater depth was detected in June. With the increase of precipitation, the groundwater depth rebounded from July to September. The irrigation water and groundwater recharge were in a relatively balanced at the seedling stage from October to December, during which time the groundwater depth was basically stable.

(3) The main factors that affected the depth of groundwater in shallow aquifer in Xingtai city were precipitation, temperature, GDP and evapotranspiration. The grey relational and wavelet coherence analysis showed that the temperature and precipitation had the most significant impacts on groundwater depth. There was a negative correlation between temperature and groundwater depth. The precipitation was negatively correlated with groundwater depth. There was a negative correlation between GDP and groundwater depth. However, there was no significant correlation between evapotranspiration and groundwater depth.

(4) The groundwater depth was predicted using two models including the multiple regression and RF model. The correlation coefficient between the predictive value and the actual value using the multiple linear regression model was 0.94 , and 0.97 for RF model, indicating that the RF model should be more suitable to predict the groundwater depth than multiple regression, mainly because the nonlinear relationships between 
groundwater depth and its influencing factors, which were also revealed by the correlation analysis.

(5) In the process of excavating the influencing factors of groundwater depth, this paper mainly considered four factors including precipitation, temperature, GDP, and evapotranspiration. However, the change of groundwater is complicated, and it will be affected by other potential factors. Future studies are recommended to consider other influencing factors that might affect the groundwater depth. In addition, time series should be extended in future studies, in order to define cycles and analyze the relevance more accurately.

Acknowledgements. The study was partly funded by the National Key Research and Development Program of China (2016YFC0401409), National Natural Science Foundation of China (51509201, 51679188), Young Technology Star in Shaanxi Province of China (Grant No. 2020KJXX-092). The Shapefile of study area was got from GADM at https://gadm.org/download_country_v3.html. The authors thank the editor and anonymous reviewers for their valuable comments and suggestions.

\section{REFERENCES}

[1] Alley, W. M., Healy, R. W., LaBaugh, J. W., Reilly, T. E. (2002): Flow and storage in groundwater systems. - Science 296(5575): 1985-1990.

[2] Bahareh, K., Husam, A. H. A., Biswajeet, P., Vahideh, S., Alfian, A. H., Naonori, U., Seyed, A. N. (2019): Optimized Conditioning Factors Using Machine Learning Techniques for Groundwater Potential Mapping. - Water 11(9): 1909.

[3] Bai, L., Cai, J., Liu, Y., Chen, H., Zhang, B. Z., Huang, L. X. (2017): Responses of field evapotranspiration to the changes of cropping pattern and groundwater depth in large irrigation district of Yellow River basin. - Agricultural Water Management 188: 1-11.

[4] Breiman, L. (2001): Random forests. - Machine Learning 45(1): 5-32.

[5] Breiman, L. (2010): Statistical modeling: The two cultures. - Statistical Science 16(3): 199-215.

[6] Chen, L., He, Q., Liu, K., Li, J., Jing, C. (2019): Downscaling of GRACE-Derived Groundwater Storage Based on the Random Forest Model. - Remote Sensing 11(24): 2979.

[7] Ebraheem, A. M., Riad, S., Wycisk, P., Sefelnasr, A. M. (2004): A local-scale groundwater flow model for groundwater resources management in Dakhla Oasis, SW Egypt. - Hydrogeology Journal 12(6): 714-722.

[8] Green, T. R., Taniguchi, M., Kooi, H., Gurdak, J. J., Allene, D. M., Hiscock, K. M., Treidel, H., Aureli, A. (2011): Beneath the surface of global change: Impacts of climate change on groundwater. - Journal of Hydrology 405(3-4): 532-560.

[9] Hong, H., Liu, J., Zhu, A. X., Shahabi, H., Pham, T. H., Chen, W., Pradhan, B., Bui, D. T. (2017): A novel hybrid integration model using support vector machines and random subspace for weather-triggered landslide susceptibility assessment in the Wuning area (China). - Environmental Earth Sciences 76: 652.

[10] Iverson, L. R., Prasad, A. M., Matthews, S. N., Peters, M. (2008): Estimating potential habitat for 134 eastern US tree species under six climate scenarios. - Forest Ecology \& Management 254(3): 390-406.

[11] Jevrejeva, S., Moore, J. C., Grinsted, A. (2003): Influence of the arctic oscillation and El Nino-Southern Oscillation (ENSO) on ice conditions in the Baltic Sea: The wavelet approach. - Journal Geophysical Resources 108(D21): 4677.

[12] Jiang, Y. (2009): China's water scarcity. - Journal of Environmental Management 90(11): 3185-3196. 
[13] Jiang, R. G., Gan, T. Y., Xie, J. C., Wang, N. (2014): Spatiotemporal variability of Alberta's seasonal precipitation, their teleconnection with large-scale climate anomalies and sea surface temperature. - International Journal of Climatology 34(9): 2899-2917.

[14] Jiang, R. G., Xie, J. C., He, H. L., Luo, J. G., Zhu, J. W. (2015): Use of four drought indices for evaluating drought characteristics under climate change in Shaanxi, China: 1951-2012. - Natural Hazards 75(3): 2885-2903.

[15] Jiang, R. G., Yu, X., Xie, J. C., Zhao, Y., Li, F. W., Yang, M. X. (2018): Recent changes in daily climate extremes in a serious water shortage metropolitan region, a case study in Jing-Jin-Ji of China. - Theoretical and Applied Climatology 134: 565-584.

[16] Jiang, R. G., Wang, Y. P., Xie, J. C., Zhao, Y., Li, F. W., Wang, X. J. (2019a): Multiscale characteristics of Jing-Jin-Ji's seasonal precipitation and their teleconnection with largescale climate indices. - Theoretical and Applied Climatology 137(1-2): 1495-1513.

[17] Jiang, R. G., Wang, Y. P., Xie, J. C., Zhao, Y., Li, F. W., Wang, X. J. (2019b): Assessment of extreme precipitation events and their teleconnections to El Nino Southern Oscillation, a case study in the Wei River Basin of China. - Atmospheric Research 218: 372-384.

[18] Jiang, R. G., Cao, R. J., Lu, X. X., Xie, J. C. Zhao, Y., Li F. W., (2020): Quantifying precipitation extremes and their relationships with large-scale climate oscillations in a tropical country, Singapore: 1980-2018. - Singapore Journal of Tropical Geography 41(3): 1-29.

[19] Li, J., Inanaga, S., Li, Z., Eneji, A. E. (2005): Optimizing irrigation scheduling for winter wheat in the North China Plain. - Agricultural Water Management 76(1): 8-23.

[20] Li, X., Li, G., Zhang, Y. (2014): Identifying Major Factors Affecting Groundwater Change in the North China Plain with Grey Relational Analysis. - Water 6(6): 15811600 .

[21] Li, P., Qian, H. (2018): Water Resources Research to Support a Sustainable China. International Journal of Water Resources Development 34: 327-336.

[22] Liu, J., Cao, G., Zheng, C. (2011): Sustainability of groundwater resources in the North China Plain. - In: Jones, J. A. A. (ed.) Sustaining Groundwater Resources. New York: Springer, pp. 69-87.

[23] Liu, Y., Jiang, X., Zhang, G., Xu, Y., Wang, X., Qi, P. (2016): Assessment of Shallow Groundwater Recharge from Extreme Rainfalls in the Sanjiang Plain, Northeast China. Water 8(10): 440.

[24] Liu, Z., Zhang, D., Wang, F., Chen, Z. (2017): Different evolving characteristics and mechanism of the influence on the groundwater depths from exploitation in the typical region of North China Plain. - Applied Ecology and Environmental Research 15(3): 725737.

[25] Manap, M. A., Nampak, H., Pradhan, B., Lee, S., Sulaiman, W. N. A., Ramli, M. F. (2014): Application of probabilistic-based frequency ratio model in groundwater potential mapping using remote sensing data and GIS. - Arabian Journal of Geosciences 7(2): 711724.

[26] Meng, S., Liu, J., Zhang, Z., Lei, T., Qian, Y., Li, Y., Fei, Y. (2015): Spatiotemporal Evolution Characteristics Study on the Precipitation Infiltration Recharge over the Past 50 Years in the North China Plain. - Journal of Earth Science 26(3): 416-424.

[27] Naghibi, S. A., Pourghasemi, H. R., Dixon, B. (2016): GIS-based groundwater potential mapping using boosted regression tree, classification and regression tree, and random forest machine learning models in Iran. - Environmental Monitoring and Assessment 188(1): 44-71.

[28] Oki, T., Kanae, S. (2006): Global hydrological cycles and world water resources. Science 313(5790): 1068-1072.

[29] Pang, Y. J., Zhang, H., Cheng, H. H., Shi, Y. L., Fang, C., Luan, X. W., Chen, S., Li, Y. H., Hao, M. (2020): The modulation of groundwater exploitation on crustal stress in the 
North China Plain, and its implications on seismicity. - Journal of Asian Earth Sciences 189: 104141.

[30] Pourghasemi, H. R., Pradhan, B., Gokceoglu, C., Mohammadi, M., Moradi, H. R. (2013): Application of weights-of-evidence and certainty factor models and their comparison in landslide susceptibility mapping at Haraz watershed, Iran. - Arabian Journal of Geosciences 6: 2351-2365.

[31] Rahmati, O., Pourghasemi, H. R., Melesse, A. M. (2016): Application of GIS-based data driven random forest and maximum entropy models for groundwater potential mapping: A case study at Mehran Region, Iran. - Catena 137: 360-372.

[32] Robertson, W. M., Sharp, J. M. (2013): Estimates of recharge in two arid basin aquifers: A model of spatially variable net infiltration and its implications (Red Light Draw and Eagle Flats, Texas, USA). - Hydrogeology Journal 21: 1853-1864.

[33] Shadmani, M., Marofi, S., Roknian, M. (2012): Trend analysis in reference evapotranspiration using Mann-Kendall and Spearman's Rho tests in arid regions of Iran. - Water Resources Management 26: 211-224.

[34] Shah, T., Roy, A. D., Qureshi, A. S., Wang, J. (2003): Sustaining Asia's groundwater boom: an overview of issues and evidence. - Natural Resources Forum 27: 130-141.

[35] Shiklomanov, I. A. (2000): Appraisal and assessment of world water resources. - Water International 25: 11-32.

[36] Sun, H., Shen, Y., Yu, Q., Flerchinger, G. N., Zhang, Y., Liu, C., Zhang, X. (2010): Effect of precipitation change on water balance and WUE of the winter wheat-summer maize rotation in the North China Plain. - Agricultural Water Management 97(8): 11391145.

[37] Tian, J., Li, C., Liu, J., Yu, F., Cheng, S., Zhao, N., Jaafar, W. Z. (2016): Groundwater Depth Prediction Using Data-Driven Models with the Assistance of Gamma Test. Sustainability 8(11): 1076.

[38] Van, B. S., Comber, A., Lamb, A. (2014): Random forest classification of salt marsh vegetation habitats using quad-polarimetric airborne SAR, elevation and optical RS data. - Remote Sensing of Environment 149: 118-129.

[39] Vidal, M., Melgar, J., Lopez, A., Santoalla, M. C. (2000): Spatial and temporal hydrochemical changes in groundwater under the contaminating effects of fertilizers and wastewater. - Journal of Environmental Management 60(3): 215-225.

[40] Wada, Y., Beek, L. P. H., Sperna, W. F. C., Chao, B. F., Wu, Y. H., Bierkens, M. F. P. (2012): Past and future contribution of global groundwater depletion to sea-level rise. Geophysical Research Letters 39(9): L09402.

[41] Wang, S., Song, X., Wang, Q., Xiao, G., Liu, C., Liu, J. (2009): Shallow groundwater dynamics in North China Plain. - Journal of Geographical Sciences 19(2): 175-188.

[42] Wang, L., Dong, Y., Xie, Y., Song, F., Wei, Y., Zhang, J. (2016): Distinct groundwater recharge sources and geochemical evolution of two adjacent sub-basins in the lower Shule River Basin, northwest China. - Hydrogeology Journal 24: 1967-1979.

[43] Yan, D. F., Jiang, R. G., Xie, J. C., Zhao, Y., Liang, J. C., Wang, Y. P. (2020): Changes in extreme temperature events and their relationships with the El Niño Southern Oscillation in the Wei River Basin, China. - Applied Ecology and Environmental Research 18(2): 2395-2412.

[44] Zhang, X., Pei, D., Hu, C. (2003): Conserving groundwater for irrigation in the North China Plain. - Irrigation Science 21: 159-166.

[45] Zhang, Y., Li, G. (2013): Long-term evolution of cones of depression in shallow aquifers in the North China Plain. - Water 5: 677-697.

[46] Zhang, Y., Wang, J., Jing, J., Sun, J. (2014): Response of groundwater to climate change under extreme climate conditions in North China Plain. - Journal of Earth Science 25(3): 612-618.

[47] Zheng, C., Liu, J., Cao, G., Kendy, E., Wang, H., Jia, Y. (2010): Can China cope with its water crisis? -Perspectives from the North China Plain. - Ground Water 48: 350-354. 
[48] Zheng, W., Wang, S., Sprenger, M., Liu, B., Cao, J. (2019): Response of soil water movement and groundwater recharge to extreme precipitation in a headwater catchment in the North China Plain. - Journal of Hydrology 576: 466-477. 